\title{
Sociodemographic factors influencing adherence to antenatal iron supplementation recommendations among pregnant women in Malawi: Analysis of data from the 2010 Malawi Demographic and Health Survey
}

\author{
A Titilayo ${ }^{1,2}$, ME Palamuleni ${ }^{1}$, O Omisakin ${ }^{2}$ \\ 1. Population Training and Research Unit, North-West University, Mafikeng, South Africa \\ 2. Department of Demography and Social Statistics, Faculty of Social Sciences, Obafemi Awolowo University, Ile-Ife, Nigeria \\ Correspondence to: Ayotunde Titilayo; E-mail: liasuayotunde@gmail.com
}

\begin{abstract}
Background and Aim

Maternal morbidity and mortality statistics remain unacceptably high in Malawi. Prominent among the risk factors in the country is anaemia in pregnancy, which generally results from nutritional inadequacy (particularly iron deficiency) and malaria, among other factors. This warrants concerted efforts to increase iron intake among reproductive-age women.

This study, among women in Malawi, examined factors determining intake of supplemental iron for at least 90 days during pregnancy.

\section{Methods}

A weighted sample of 10,750 women (46.7\%), from the 23,020 respondents of the 2010 Malawi Demographic and Health Survey (MDHS), were utilized for the study. Univariate, bivariate, and regression techniques were employed. While univariate analysis revealed the percent distributions of all variables, bivariate analysis was used to examine the relationships between individual independent variables and adherence to iron supplementation. Chi-square tests of independence were conducted for categorical variables, with the significance level set at $\mathrm{P}<0.05$. Two binary logistic regression models were used to evaluate the net effect of independent variables on iron supplementation adherence.
\end{abstract}

\section{Results}

Thirty-seven percent of the women adhered to the iron supplementation recommendations during pregnancy. Multivariate analysis indicated that younger age, urban residence, higher education, higher wealth status, and attending antenatal care during the first trimester were significantly associated with increased odds of taking iron supplementation for 90 days or more during pregnancy $(\mathrm{P}<0.01)$.

\section{Conclusions}

The results indicate low adherence to the World Health Organization's iron supplementation recommendations among pregnant women in Malawi, and this contributes to negative health outcomes for both mothers and children. Focusing on education interventions that target populations with low rates of iron supplement intake, including campaigns to increase the number of women who attend antenatal care clinics in the first trimester, are recommended to increase adherence to iron supplementation recommendations.

\section{Introduction}

The menace of maternal mortality continues to be a great concern in sub-Saharan Africa. Despite all efforts put in place to achieve Millennium Development Goal 5 (reducing maternal deaths by a minimum of $75 \%$ and achieving universal access to reproductive health by the end of 2015), the risk of death from pregnancy or childbirth-related morbidity is as much as 200 times higher in sub-Saharan Africa than in most of the developed world. ${ }^{1}$ Malawi, with about 510 maternal deaths per 100,000 live births, ${ }^{2}$ still has one of the highest maternal mortality ratios in the world. The common causes of these often-preventable deaths are well known: haemorrhage, infection and sepsis, hypertensive disorders of pregnancy, complications of unsafe abortion, iron-deficiency and malaria-borne anaemia, and obstructed or prolonged labour. Despite these known risk factors and efforts to combat them, a substantial reduction in maternal deaths in Malawi has remained elusive. Although accurate prevalence rates in many countries are unknown, the prevalence of anaemia in pregnancy, as a contributing factor to maternal mortality, is estimated to be $35 \%$ to $75 \%$ in African countries. ${ }^{3-6}$ Iron deficiency anaemia alone has been estimated to account for more than $85 \%$ of nutritional anaemia ${ }^{7}$ and is a significant predictor of about one-quarter of maternal deaths around the world. ${ }^{8}$ Severe iron deficiency anaemia is estimated to contribute to more than 50,000 yearly global maternal deaths among young women. ${ }^{9}$

Iron deficiency anaemia occurs when the intake or absorption of iron-rich nutrition is inadequate for the production of haemoglobin, the oxygen-carrying component of red blood cells. The World Health Organization (WHO) defines anaemia in pregnancy as haemoglobin levels of less than $11.0 \mathrm{~g} / \mathrm{dL} .^{3}$ Iron deficiency is the commonest nutritional deficiency and, if uncorrected, can lead to anaemia of 
higher severity and increased susceptibility to infection, which thereby makes it a significant predictor of morbidity and mortality among pregnant women, especially during and immediately after delivery. Further consequences of anaemia in pregnancy include cardiovascular dysfunction, reduced physical and mental performance, reduced immune function, reduced peripartum blood reserves, and increased risk of blood transfusion in the postpartum period. ${ }^{10-12}$

To ameliorate the effect of iron deficiency anaemia in pregnancy, iron supplementation has been proposed as a necessity for all pregnant women, especially in developing countries where dietary iron intake is often insufficient. ${ }^{13-15}$ The prescription of iron (tablets or syrup) and folic acid supplements in pregnancy has long been a common practice in most countries, ${ }^{7,16}$ but non-adherence to such recommendations remains an issue. ${ }^{7,17,18}$ Reasons for poor adherence or compliance to iron supplementation prescriptions include complaints of side effects and a lack of public awareness of the importance of supplementation.

Considering the implications of anaemia on reproductive health outcomes in Malawi, this study utilized the most recent nationally representative women's data from the 2010 Malawi Demographic and Health Survey (MDHS) ${ }^{19}$ to examine the relationship between Malawian women's socioeconomic characteristics and their adherence to iron supplement usage for at least 90 days during their most recent pregnancies.

\section{Methods}

\section{Data}

The study used secondary data extracted from the 2010 MDHS, which includes the most recent nationally representative data. To minimize recall bias, the study population was limited to women who gave birth within three years of completing the survey. To ensure a nationally representative sample for this analysis, we used a weighted subsample of $10,750(46.7 \%)$ of the 23,020 women who responded to the 2010 MDHS.

\section{Dependent variable}

The dependent variable for the study was adherence to routine iron supplementation within the period of pregnancy of the most recent birth; this was measured in the MDHS by the number of days that iron supplements were taken within the period of pregnancy of the most recent birth. The continuous responses of the dependent variable were recorded in two categories (less than 90 days and 90 days or more). Recoding the continuous responses into two categories was informed by the WHO recommendation that a pregnant women should take iron supplements for at least 90 days during the antenatal period. Therefore, respondents who used iron supplements for at least 90 days in their last pregnancy were grouped as adherent to the recommendation, and the women who took iron supplements for less than 90 days were grouped as non-adherent.

\section{Independent variables}

A number of independent variables were applied to examine possible significant determinants of adherence. The independent variables and the respective stratifications for this study were as follows: age of respondents in years (1519, 20-29, 30-39, 40-49); place of residence (urban, rural); highest educational level (low $=$ no education or primary, high $=$ secondary and higher); religion (Christian, Islam, other); wealth (poor, middle, rich); age at first childbirth (less than 20 years, 20 years and above); number of live births (4 or less, more than 4); timing of first antenatal visit (first trimester, second trimester, third trimester).

\section{Data analysis}

Univariate, bivariate, and regression techniques were employed to achieve the research objective. While univariate analysis revealed the percent distributions of all variables, bivariate analysis was used to examine the relationships between individual independent variables and adherence to iron supplementation. Chi-square tests of independence were conducted for categorical variables and significant differences were determined using chi-square, with the significance level set at $\mathrm{P}<0.05$. Two binary logistic regression models (suitable because of the dichotomous nature of the dependent variable) were used to evaluate the net effect of the background characteristics (independent variables) on iron supplementation adherence (dependent variable). The first binary logistic regression model tested the influence of the respondents' socioeconomic characteristics on the odds of adherence to iron supplementation, and the second model presented the total net effect of the respondents' socioeconomic, demographic, and health characteristics on adherence. All data analysis for this study was based on the weighted subsample size of 10,750 women, and all analyses were carried out using SPSS version 21.

\section{Results}

Table 1 shows the socioeconomic and demographic characteristics of the respondents, namely respondent age, place of residence, highest educational level, religion, wealth status, age at first childbirth, number of live births, timing of the first antenatal visit, and intake of iron supplements during the last pregnancy. The mean age of the sampled respondents was 27.5 years, with the minimum and maximum ages being 15 and 48 years, respectively. The age group with the fewest number of respondents was the 40-49-year group, which accounted for $6.3 \%$ of the sampled participants, while fewer than $30 \%$ of the respondents were 30 to 39 years of age. Eighty-five percent of respondents resided in rural areas, while the rest $(15 \%)$ were urban dwellers. Most respondents $(84.2 \%)$ had less than secondary school education, and only $1 \%$ acquired higher education.

Christians constituted $84 \%$ of the sample, while $15 \%$ were Muslim. Forty-three percent of the respondents were categorized as poor, $22 \%$ were of intermediate wealth status, and $35 \%$ were categorized as rich. Most of the respondents $(70 \%)$ delivered their first-born children before the age of 20 years, and most $(70 \%)$ had delivered four or fewer live children at the time of the survey. Thirteen percent of respondents had an initial antenatal visit during the first trimester of the most recent pregnancy, whereas $74 \%$ first attended antenatal care during the second semester, and 13\% during the third trimester. Nearly two-thirds $(63 \%)$ of the respondents reported taking iron supplements for less than 90 days during the most recent pregnancy, while the remaining third adhered to the WHO's minimum recommendation for iron supplementation duration in pregnancy. 
Table 1: Frequency and percent distributions of respondents socioeconomic and demographic characteristics and select survey responses

\begin{tabular}{|c|c|c|}
\hline Variables/categories & Frequency & Percentage \\
\hline \multicolumn{3}{|l|}{ Age } \\
\hline $15-19$ & 956 & 8.9 \\
\hline $20-29$ & 6113 & 56.9 \\
\hline $30-39$ & 3005 & 28.0 \\
\hline $40-49$ & 678 & 6.3 \\
\hline \multicolumn{3}{|l|}{ Place of residence } \\
\hline Urban & 1568 & 14.6 \\
\hline Rural & 9182 & 85.4 \\
\hline \multicolumn{3}{|l|}{ Highest educational level } \\
\hline Low education (primary or none) & 9054 & 84.2 \\
\hline High education (secondary or higher) & 1696 & 15.8 \\
\hline \multicolumn{3}{|l|}{ Religion $* *$} \\
\hline Christian & 9009 & 83.9 \\
\hline Islam & 1591 & 14.8 \\
\hline Other & 140 & 1.3 \\
\hline \multicolumn{3}{|l|}{ Wealth status } \\
\hline Poor & 4647 & 43.2 \\
\hline Middle & 2326 & 21.6 \\
\hline Rich & 3777 & 35.1 \\
\hline \multicolumn{3}{|l|}{ Age at first childbirth } \\
\hline Less than 20 years & 7569 & 70.4 \\
\hline 20 years or more & 3181 & 29.6 \\
\hline \multicolumn{3}{|l|}{ Number of live births } \\
\hline 4 or less & 7523 & 70.0 \\
\hline More than 4 & 3227 & 30.0 \\
\hline \multicolumn{3}{|c|}{ Timing of first antenatal visit during the } \\
\hline last pregnancy** & 1334 & 12.6 \\
\hline First trimester & 7828 & 74.2 \\
\hline Second trimester & 1395 & 13.2 \\
\hline \multicolumn{3}{|l|}{ Third trimester } \\
\hline \multicolumn{3}{|l|}{$\begin{array}{l}\text { Days iron tablets or syrup were taken } \\
\text { during the last pregnancy** }\end{array}$} \\
\hline Less than 90 days & 5902 & 62.8 \\
\hline 90 days or more & 3501 & 37.2 \\
\hline
\end{tabular}

Employing chi-square to measure the association between dependent and independents variables, Table 2 describes the associations between the socioeconomic, demographic, and other background variables and the level of adherence to iron supplementation among the respondents. Significant differences $(\mathrm{P}<0.01)$ were found among the individual categories of each independent variable evaluated in this study. The percentage of respondents who took iron supplements for 90 days or more was highest among the youngest age group (15-19 years), with almost $44 \%$ of them adhering to the WHO guideline and progressively fewer adherent respondents in each of the subsequently older age groups. In terms of place of residence, respondents from urban areas were significantly more likely take iron supplements for 90 days or more during pregnancy. Highly educated respondents were significantly more likely to be adherent than respondents who had an education below the secondary school level. Religious differences among the respondents also proved significant in terms of their influence on adherence to iron supplementation, with Islamic respondents more likely than other religious groups to be adherent. Likelihood of adherence to the WHO recommendation on iron supplementation during pregnancy among Malawian women was also significantly associated with a higher socioeconomic status, being 20 years of age or older at first childbirth, having had four or fewer deliveries of live infants, and earlier initiation into antenatal care.
Table 2: Percent distributions of respondents' backoround characteristics by adherence to the WHO's iron supplementation recommendation

\begin{tabular}{|c|c|c|c|}
\hline \multirow[t]{2}{*}{ Variables/categories } & \multicolumn{2}{|c|}{$\begin{array}{c}\text { Days iron tablets or syrup } \\
\text { were taken during the last } \\
\text { pregnancy }\end{array}$} & \multirow[t]{2}{*}{$P$ value } \\
\hline & $\begin{array}{l}\text { Less than } 90 \\
\text { days }(\%)\end{array}$ & $\begin{array}{l}90 \text { days or } \\
\text { more }(\%)\end{array}$ & \\
\hline \multicolumn{4}{|l|}{ Age } \\
\hline $15-19$ & 58.3 & 43.7 & \multirow{4}{*}{$<0.001$} \\
\hline $20-29$ & 62.1 & 37.9 & \\
\hline $30-39$ & 65.5 & 34.5 & \\
\hline $40-49$ & 66.2 & 33.8 & \\
\hline \multicolumn{3}{|l|}{ Place of residence } & \multirow{3}{*}{$<0.001$} \\
\hline Urban & 53.2 & 46.8 & \\
\hline Rural & 64.4 & 35.6 & \\
\hline \multicolumn{3}{|l|}{ Highest educational level } & \multirow{3}{*}{$<0.001$} \\
\hline Low education (primary or none) & 64.2 & 35.8 & \\
\hline High education (secondary or higher) & 55.6 & 44.4 & \\
\hline \multicolumn{3}{|l|}{ Religion } & \multirow{4}{*}{$<0.001$} \\
\hline Christian & 63.9 & 36.1 & \\
\hline Islam & 56.4 & 43.6 & \\
\hline Other & 61.4 & 38.6 & \\
\hline \multicolumn{3}{|l|}{ Wealth status } & \multirow{4}{*}{$<0.001$} \\
\hline Poor & 66.4 & 33.6 & \\
\hline Middle & 61.9 & 38.1 & \\
\hline Rich & 58.9 & 41.1 & \\
\hline \multicolumn{3}{|l|}{ Age at first childbirth } & \multirow{3}{*}{0.002} \\
\hline Less than 20 years & 63.8 & 36.2 & \\
\hline 20 years or more & 60.4 & 39.6 & \\
\hline \multicolumn{3}{|l|}{ Number of live births } & \multirow{3}{*}{$<0.001$} \\
\hline 4 or less & 61.3 & 38.7 & \\
\hline More than 4 & 66.4 & 33.6 & \\
\hline \multicolumn{3}{|l|}{$\begin{array}{l}\text { Timing of first antenatal visit } \\
\text { during the last pregnancy }\end{array}$} & \multirow{4}{*}{$<0.001$} \\
\hline First trimester & 52.8 & 47.2 & \\
\hline Second trimester & 60.5 & 39.5 & \\
\hline Third trimester & 85.6 & 14.4 & \\
\hline
\end{tabular}

Table 3 presents the results of the binary logistic regression models of adherence to 90 or more days of iron supplementation during pregnancy by predictor variables. Model 1 explains the relationship between socioeconomic variables and adherence, while model 2 includes the socioeconomic and other background variables, such as age at first childbirth, number of live births, and timing of the first antenatal visit, as predictors of adherence to the WHO iron supplementation recommendation.

The results from the two binary logistic regression models indicate that, with the exceptions of religion, age at first childbirth, and number of live births, all other background variables were significantly associated with the odds of adherence to at least 90 days of iron supplementation during pregnancy. With respect to respondent age, the odds of adherence were significantly greater among women in the 15-19 age group $(\mathrm{P}<0.01)$. The likelihood of adherence decreased with each sequential age group increase. In terms of place of residence, the odds of adherence were significantly higher among urban dwellers by $40 \%$ and $42 \%$ in models 1 and 2, respectively. Regarding educational level, the odds of adherence were $21 \%$ and $17 \%$ more likely (in models 1 and 2, respectively) among those with at least a secondary education compared to those with lower levels of education. Although the respondents' religious beliefs did not have a statistically significant impact on adherence, Muslim respondents were more likely to be adherent than others. Respondents who were categorized as poor were less likely to be adherent than their rich counterparts in both models.

The results in model 2 show the impact of age at first childbirth, number of live births, and the timing of the first antenatal visit. Respondents who were younger than 20 years old when giving birth for the first time were $12 \%$ less likely to be adherent than those 20 years of age or older at first childbirth. Respondents who had delivered 4 or fewer live infants at the time of the survey were about $2 \%$ less 
likely to adhere than those who had delivered more than 4 babies. Adherence varied significantly according to the timing of the respondents' first antenatal visits during the most recent pregnancy $(\mathrm{P}<0.01)$. Respondents who first attended antenatal clinic during the first trimester were five times more likely to adhere than those who first attended in the third trimester, and those who first attended during the second trimester were four times more likely to adhere than those who delayed until the third trimester.

Table 3: Odds ratios (binary logistic regression models) of adherence to 90 or more days of iron supplementation during pregnancy by selected independent variables

\begin{tabular}{|c|c|c|c|}
\hline Variables/categories & Model 1 & $95 \% \mathrm{CI}$ & Model 2 \\
\hline \multicolumn{4}{|l|}{ Age } \\
\hline $15-19$ & $1.45^{* * *}$ & $1.16-1.80$ & $1.38^{* *}$ \\
\hline $20-29$ & 1.10 & $0.92-1.33$ & 1.04 \\
\hline $30-39$ & 0.99 & $0.81-1.19$ & 0.96 \\
\hline $40-49 \mathrm{RC}$ & 1.00 & & 1.00 \\
\hline \multicolumn{4}{|l|}{ Place of residence } \\
\hline Urban & $1.40^{* * *}$ & $1.23-1.59$ & $1.42^{* * *}$ \\
\hline RuralRC & 1.00 & & 1.00 \\
\hline \multicolumn{4}{|l|}{ Highest educational level } \\
\hline Low (primary or none) & $0.79^{* * *}$ & $0.70-0.89$ & $0.83 * * *$ \\
\hline High (secondary or higher) ${ }^{\mathrm{RC}}$ & 1.00 & & 1.00 \\
\hline \multicolumn{4}{|l|}{ Religion } \\
\hline Christian & 0.82 & $0.56-1.20$ & 0.81 \\
\hline Islam & 1.17 & $0.79-1.73$ & 1.14 \\
\hline Other ${ }^{\mathrm{RC}}$ & 1.00 & & 1.00 \\
\hline \multicolumn{4}{|l|}{ Wealth status } \\
\hline Poor & $0.86^{*}$ & $0.77-0.95$ & $0.86^{*}$ \\
\hline Middle & 1.00 & $0.89-1.13$ & 0.99 \\
\hline $\operatorname{Rich}^{\mathrm{RC}}$ & 1.00 & & 1.00 \\
\hline \multicolumn{4}{|l|}{ Age at first childbirth } \\
\hline Less than 20 years & & & $0.88^{* *}$ \\
\hline 20 years or more ${ }^{\mathrm{RC}}$ & & & 1.00 \\
\hline \multicolumn{4}{|l|}{ Number of live births } \\
\hline 4 or less & & & 0.98 \\
\hline More than $4 \mathrm{RC}$ & & & 1.00 \\
\hline \multicolumn{4}{|l|}{$\begin{array}{l}\text { Timing of first antenatal } \\
\text { visit during last pregnancy }\end{array}$} \\
\hline First trimester & & & $5.18^{* * *}$ \\
\hline Second trimester & & & $3.76^{* * *}$ \\
\hline Third trimester ${ }^{\mathrm{RC}}$ & & & 1.00 \\
\hline$-2 \cdot \log$ likelihood & 12250.32 & & 11860.33 \\
\hline Chi-square (df) & $150.34(9)$ & & $504.14(13)$ \\
\hline Significance & 0.00 & & 0.00 \\
\hline
\end{tabular}

\section{Discussion}

Our findings showed that the majority of respondents (63\%) did not comply with the recommended minimum duration of iron supplementation during pregnancy. The low level of adherence among pregnant women in Malawi, as reported in the 2010 MDHS and detailed in this article, is in line with findings from other studies..$^{20,21}$ The high prevalence of iron deficiency anaemia and the low adherence to iron supplementation recommendations contribute substantially to the high morbidity and mortality levels among women of reproductive age in Malawi.

Age correlated negatively with adherence. This perhaps shows that some women relied on their previous experiences of pregnancy and childbirth and that their attitudes towards health and safety precautions changed as they grew older (and perhaps experienced multiple uneventful pregnancies despite a lack of adherence, whether or not they were anaemic). Despite the higher prevalence of iron deficiency anaemia among women in rural Malawi, ${ }^{22}$ respondents from urban areas exhibited greater adherence to iron supplementation than their rural counterparts. The reasons for the urban-rural difference could be related to unequal opportunities, as is often the case in developing countries, where urban settings have better access to health care services than rural settings. http://dx.doi.org/10.4314/mmj.v28i1.1
Higher education and increased wealth were associated with greater adherence to iron supplementation. This finding is supported by studies done in India and Ethiopia. ${ }^{20}$ Educated and wealthy women are likely to have better knowledge and access to information about iron deficiency anaemia and therapy, the benefits of supplements, and pregnancy in general. Education, wealth, and access to information are inextricable from the findings related to some of the other independent variables evaluated in this exercise, and it follows accordingly that rural residence, early age at first childbirth, and late first attendance at antenatal care were associated with non-adherence. The results reinforce the need for improvements in the education, economic participation, and level of income for women of reproductive age in Malawi, as few of the women had secondary (15\%) and higher $(1 \%)$ education, and "poor" (43\%) was the most well-represented wealth category.

\section{Study limitations}

This study relied solely on secondary data, which prevented the capturing of potentially revealing study outcomes, such as attitudes of service providers towards clients, waiting times to receive services, and costs. Secondly, the data, selfreported by the study participants, was susceptible to recall bias (even though, as mentioned above, effort was made to minimize this limitation), since respondents had to recall information from as long as three years prior to the survey.

\section{Conclusions}

Understanding the links between the sociodemographic characteristics of pregnant women and their adherence to iron supplementation guidelines is of key significance to improving reproductive health outcomes in Malawi. Strategies to address the problem of iron deficiency anaemia should focus on at-risk women. All pregnant women should be encouraged to initiate antenatal care during the first trimester, so they can receive advice on routine iron supplementation early in pregnancy and benefit from the entirety of the focused antenatal care package. Adherence to routine iron supplementation and reducing the prevalence of iron deficiency anaemia in pregnancy could prevent the need for costlier interventions, at later stages, that could also pose further risks to maternal and child health. ${ }^{23}$ Educational interventions that target populations with low intake of iron supplementation should to be developed as part of the efforts to mitigate the reproductive and maternal health challenges facing the country.

\section{Acknowledgements}

The authors gratefully acknowledge the National Statistical Office (NSO) and ICF Macro for making the MDHS data available for public use. The authors wish to state that views expressed in this article are solely those of the authors, and not of the DHS Programme.

\section{References}

1. World Health Organization, United Nations Children's Emergency Fund. Revised 1990 estimates of maternal mortality: a new approach by WHO and UNICEF. Geneva: World Health Organization; 1996.

2. Countdown to 2015. A decade of tracking progress for maternal, newborn, and child survival: the 2015 report - Malawi [Internet]. Geneva: UNICEF and World Health Organization; 2015 [cited 2015 Dec 2].

3. World Health Organization. The prevalence of anaemia in women: a tabulation of available information. 2nd ed. Geneva: World Health 
Organization; 1992

4. Meda N, Mandelbrot L, Cartoux M, Dao B, Ouangré A, Dabis F. Anaemia during pregnancy in Burkina Faso, west Africa, 1995-96: prevalence and associated factors. DITRAME Study Group. Bull World Health Organ. 1999;77(11):916-22.

5. National Bureau of Statistics (NBS) [Tanzania], ICF Macro. Tanzania demographic and health survey 2010. Dar es Salaam: NBS and ICF Macro; 2011.

6. Haggaz AD, Radi EA, Adam I. Anaemia and low birthweight in western Sudan. Trans R Soc Trop Med Hyg. 2010 Mar;104(3):234-6. doi: 10.1016/j.trstmh.2009.07.013.

7. Zamani A, Farajzadegan Z, Ghahiri A, Khademloo M, Golshiri, P. Effectiveness of twice weekly iron supplementation compared with daily regimen in reducing anemia and iron deficiency during pregnancy: a randomized trial in Iran. J Res Med Sci. 2008 Oct;13(5):230-9.

8. Wondu T, Bijlsma M. The hidden hunger: understanding the burden of anaemia and its determinants among pregnant and non-pregnant women in Ethiopia. African Journal of Food, Agriculture, Nutrition, and Development: 2012 Dec;12(7):6913-30.

9. Hussar DA. New drugs: pregabalin and omega-3-acid ethyl esters. J Am Pharm Assoc (2003). 2005 Nov-Dec;45(6):765-7.

10. Baker WF Jr. Iron deficiency in pregnancy, obstetrics, and gynecology. Hematol Oncol Clin North Am. 2000 Oct;14(5):1061-77.

11. van den Broek NR, Letsky EA. Etiology of anemia in pregnancy in south Malawi. Am J Clin Nutr. 2000 Jul;72(1 Suppl):247S-256S.

12. Bondevik GT, Eskeland B, Ulvik RJ, Ulstein M, Lie RT, Schneede J, et al. Anaemia in pregnancy: possible causes and risk factors in Nepali women. Eur J Clin Nutr. 2000 Jan;54(1):3-8.

13. Bodnar LM, Cogswell ME, Scanlon KS. Low income postpartum women are at risk of iron deficiency. J Nutr. 2002 Aug;132(8):2298302.

14. Milman N, Bergholt T, Eriksen L, Byg KE, Graudal N, Pedersen P, et al. Iron prophylaxis during pregnancy - how much iron is needed? A randomized dose-response study of 20-80 $\mathrm{mg}$ ferrous iron daily in pregnant women. Acta Obstet Gynecol Scand. 2005 Mar;84(3):238-47.
15. Khalid S, Waqar S, Faisal M, Ahmad SI. Effectiveness of weekly iron supplementation in anemia in pregnancy. Pakistan Journal of Pharmacology. 2011 Jan;28(1):9-16.

16. Huddle JM, Gibson RS, Cullinan TR. The impact of malarial infection and diet on the anaemia status of rural pregnant Malawian women. Eur J Clin Nutr. 1999 Oct;53(10):792-801.

17. Viteri FE, Xunian L, Tolomei K, Martin A. True absorption and retention of supplemental iron is more efficient when iron is administered every three days rather than daily to iron-normal and irondeficient rats. J Nutr. 1995 Jan;125(1):82-91.

18. Kianfar H, Kimiagar M, Ghaffarpour M. Effect of daily and intermittent iron supplementation on iron status of high school girls. Int J Vitam Nutr Res. 2000 Jul;70(4):172-7.

19. National Statistical Office (NSO) and ICF Macro. Malawi demographic and health survey 2010. Zomba, Malawi, and Calverton, Maryland, USA: NSO and ICF Macro; 2011.

20. Taye B, Abeje G, Mekonen A. Factors associated with compliance of prenatal iron folate supplementation among women in Mecha district, Western Amhara: a cross-sectional study. Pan Afr Med J. 2015 Jan 15;20:43. doi: 10.11604/pamj.2015.20.43.4894.

21. Titilayo A, Agunbiade OM. Iron deficiency anemia in pregnancy: implication for reproductive health in Nigeria. Journal of Demography and Social Statistics (Ife-Ife, Nigeria: Obafemi Awolowo University Press): 2014;1(1):98-109.

22. van den Broek NR, Rogerson SJ, Mhango CG, Kambala B, White SA, Molyneux ME. Anaemia in pregnancy in southern Malawi: prevalence and risk factors. BJOG. $2000 \mathrm{Apr} ; 107(4)$ :445-51

23. Candio F, Hofmeyr GJ. Treatments for iron-deficiency anaemia in pregnancy: RHL Commentary. The WHO Reproductive Health Library [Internet]. Geneva: World Health Organization; 2007 [cited 2015 Aug 27]. Available from: http://apps.who.int/rhl/pregnancy childbirth/ medical/anaemia/cfcom/en/. 